\title{
Explorando conceitos de Reações Químicas por meio do Método Jigsaw de Aprendizagem Cooperativa
}

Fabiele Cristiane Dias Broietti fabieledias@uel.br

0000-0002-0638-3036

Universidade Estadual de Londrina,

Paraná, Brasil.

Miriam Cristina Covre de Souza

$\frac{\text { miriam.covre@gmail.com }}{\text { 0000-0001-6473-196X }}$

Universidade Estadual de Londrina,

Paraná, Brasil.

\begin{abstract}
RESUMO
Este artigo descreve uma proposta de atividade baseada na aprendizagem cooperativa usando o método Jigsaw. A atividade, desenvolvida com bolsistas do projeto PIBID/Química de uma universidade pública do Paraná, abordou conceitos de Reações Químicas e discutiu as possibilidades de implementação desse método em turmas do Ensino Médio. Os resultados, obtidos por meio de questionário e discussão, apontam que o método Jigsaw pode: propiciar uma forma mais organizada de trabalho em grupos cooperativos, uma vez que os integrantes atuam com funções específicas e imprescindíveis ao grupo; oportunizar o desenvolvimento ou aperfeiçoamento de habilidades, tais como fala, escrita, organização de ideias, resolução de conflitos de opinião; possibilitar condições de (re)significação conceitual, por meio das discussões nos distintos grupos (base e especialistas); contribuir para que os estudantes tenham um papel mais ativo no processo de aprendizagem; e estimular o papel de mediador do professor ao elaborar, organizar e desenvolver a proposta envolvendo o método.
\end{abstract}

PALAVRAS-CHAVE: Jigsaw. PIBID. Reações químicas. Aprendizagem cooperativa. 


\section{INTRODUÇÃO}

A aprendizagem em grupo, ou aprendizagem cooperativa, de acordo com Andrade (2011), é uma metodologia muito antiga que surgiu em várias civilizações. Nos séculos III e IV a.C., já se tinha ideia de agrupar duas ou mais pessoas para trabalharem em conjunto, a fim de obterem melhores aprendizagens. Durante os séculos XVIII e XIX, surgem alguns trabalhos e obras acerca do método de aprendizagem em pequenos grupos, com destaque para Andrew Bell, que desenvolveu o método de ensino mútuo, a partir do qual os estudantes com mais capacidades ensinavam os com mais dificuldades.

Nas primeiras décadas do século XX, autores ligados à psicologia, nomeadamente Vygotsky, deram um contributo importante para o desenvolvimento das bases teóricas explicativas da aprendizagem cooperativa. Contudo, os primeiros estudos acerca da influência do trabalho em grupo com crianças em escolas ocorreram somente na década de 1930, os quais demonstraram que crianças trabalhando em grupos cooperativos democráticos revelavam melhores resultados escolares do que aquelas que trabalhavam em grupos com presença de uma liderança autoritária. No final da primeira metade do século XX, Morton Deutsch realizou uma investigação sobre os efeitos da cooperação e da competição nos grupos, demonstrando que em uma situação de aprendizagem cooperativa havia uma maior produtividade (FREITAS e FREITAS, 2003).

A aprendizagem cooperativa teve o seu desenvolvimento pleno somente em meados dos anos 1970, nos Estados Unidos da América, principalmente pelos irmãos David Johnson e Roger Johnson (FATARELI et al., 2010) e investigadores como Robert Slavin, Spencer Kagan e Elizabeth Cohen, que realizaram um trabalho mais sistemático acerca da formação, do desenvolvimento e da avaliação de atividades em grupos, revelando a eficácia dessa metodologia de aprendizagem, que passou a ser considerada como um conjunto de técnicas a serem utilizadas consistentemente nas aulas (FREITAS e FREITAS, 2003).

Assim, a aprendizagem cooperativa começou a ser vista como um método de ensino e de aprendizagem no qual pequenos grupos de alunos trabalham em conjunto para maximizar a sua própria aprendizagem e a dos seus colegas (JOHNSON, JOHNSON e HOLUBEC, 1999).

Fatareli et al. (2010, p. 161) destacam que "uma característica dessa aprendizagem é a sua natureza social, pois os estudantes interagem e compartilham suas ideias, melhorando sua compreensão individual e mútua". As ideias de Fatareli et al. (2010) corroboram as de Maset (2003), uma vez que este acredita que o método cooperativo é baseado em dois pilares essenciais: a aprendizagem, que exige a participação direta e ativa dos estudantes, pois ninguém pode aprender pelo outro, no máximo pode ajudá-lo; e a assistência e a cooperação mútua, que, em condições adequadas, possibilitam atingir níveis mais altos de aprendizagem, de melhor qualidade.

Valadares e Moreira (2009) comentam que, por meio do trabalho cooperativo, os estudantes são capazes de construir, modificar e integrar ideias, chegando mais além do que conseguiriam individualmente. Díaz-Aguado (2000) ressalta também uma eficácia no nível de motivação pela aprendizagem, do sentido de responsabilidade, das relações interétnicas, da tolerância e da capacidade de 
cooperação dos estudantes envolvidos. Assim, a aprendizagem passa a ser também um processo de interação social e não somente individualista (ANDRADE, 2011), indo ao encontro das exigências da sociedade contemporânea, que prioriza a revalorização das competências sociais dos indivíduos e sua capacidade de agir coletiva e democraticamente (BESSA e FONTAINE, 2002).

Para atingir tais exigências, Johnson, Johnson e Holubec (1999) destacam que uma característica essencial dos grupos de cooperação é a heterogeneidade em relação ao aproveitamento escolar, gênero, idade, classe social, entre outras características, permitindo que os grupos possam refletir as características da turma, uma vez que a diversidade dos elementos que integram o grupo é uma das premissas para a promoção da aprendizagem cooperativa (ANDRADE, 2011).

Cochito (2004) destaca que algumas das modalidades de aprendizagem cooperativa mais divulgadas e que têm sido objeto de extensa investigação são: Aprender Juntos, Instrução Complexa, o TGT (Teams-Games-Tournament), o STAD (Student Teams Achievement Division), Estruturas Cooperativas, Investigação de Grupo e Grupo de Especialistas (Jigsaw).

Dessas modalidades, a de interesse no artigo em questão é a de Grupo de especialistas, conhecida como método Jigsaw.

O método Jigsaw foi desenvolvido por Aronson et al. (1978) e não se distancia dos princípios enunciados por Johnson e Johnson (1974); caracteriza-se por um conjunto de procedimentos específicos, especialmente adequado ao desenvolvimento de competências cognitivas (FATARELI et al., 2010; COCHITO, 2004) e baseia-se numa perspectiva motivacional (BARBOSA e JÓFILI, 2004).

Esse método foi usado pela primeira vez em 1971, nos Estados Unidos, durante o período de luta pelos direitos civis, quando jovens brancos, afroamericanos e hispânicos começaram a frequentar, pela primeira vez, a mesma escola. Aronson percebeu que a desconfiança era mútua e os conflitos eclodiam frequentemente e, ao discutir a questão com os alunos, chegou à conclusão que o problema estava no tipo de estrutura da sala de aula, em que os alunos trabalhavam individualmente e competiam entre si pelas melhores notas. Após essa análise, a solução encontrada foi estruturar o trabalho de forma colaborativa, em grupos de especialistas (COCHITO, 2004; BESSA e FONTAINE, 2002).

O método Jigsaw consiste em juntar alunos em pequenos grupos de estudo, nos quais o trabalho realizado por cada um é indispensável para a concretização do produto final. Cochito $(2004$, p. 31 ) explica que "tudo funciona como num puzzle que só está concluído quando todas as peças estão perfeitamente encaixadas".

Segundo Cochito (2004), Fatareli et al. (2010) e Barbosa e Jófili (2004), na primeira fase, os estudantes são distribuídos por grupos heterogêneos (grupo de base) e os conteúdos a serem estudados são divididos em tantas seções quanto os elementos do grupo. Na segunda fase, cada estudante estuda e discute a parte do conteúdo que Ihe foi designada, juntamente com os colegas dos outros grupos a quem foram destinados, formando, assim, um grupo de especialistas. Posteriormente, na terceira fase, cada estudante retorna ao grupo de base inicial e apresenta o que aprendeu aos seus colegas, de maneira que fiquem reunidos os conhecimentos indispensáveis para a concretização do trabalho do grupo. Nesse método, "cada aluno tem de aprender o conteúdo para 'si próprio' e também de 
explicar aos seus colegas, de forma clara, o que aprendeu, uma vez que todos vão ser avaliados, de forma individual, sobre todos os conteúdos estudados" (COCHITO, 2004, p. 31).

Nessa lógica, o trabalho de cada um dentro do grupo é imprescindível, uma vez que o papel de cada estudante se torna essencial, motivo esse do sucesso do método, pois os estudantes, além de aprenderem o conteúdo, também aprendem uns com os outros acerca da forma de expor os conceitos. Desenvolvem também competências sociais e argumentativas, bem como a autonomia e a responsabilidade individual (COCHITO, 2004; SÁ, 2015).

\section{O Método Jigsaw no Ensino de Ciências}

$\mathrm{Na}$ literatura encontram-se alguns artigos que apresentam propostas de atividades para o ensino de conteúdos científicos com o uso da abordagem cooperativa, em particular do método Jigsaw (BARBOSA e JÓFILI, 2004; FATARELI et al. 2010; LEITE et al. 2013; MASSI, CERRUTTI e QUEIROZ, 2013; OLIVEIRA e KIOURANIS, 2014; WINSCHEL et al. 2015; TEODORO, CABRAL e QUEIROZ, 2015).

Barbosa e Jófili (2004) propõem, em seu estudo, investigar a influência dos métodos cooperativos, entre eles o Jigsaw, no desenvolvimento de atitudes cooperativas entre estudantes do Ensino Fundamental e Superior, com vistas tanto na aprendizagem significativa de química quanto no desenvolvimento de atitudes éticas relacionadas a essa ciência. Os autores ressaltam aspectos positivos desse tipo de abordagem e reforçam a necessidade de os professores experimentarem combinações entre diferentes métodos, de forma a contemplar, além do desenvolvimento cognitivo, outras competências e habilidades necessárias à formação integral do estudante.

Fatareli et al. (2010) descrevem resultados de uma estratégia didática baseada na aprendizagem cooperativa, método Jigsaw, aplicada em uma aula de Química do Ensino Médio de uma escola paulista. Os autores avaliam possíveis contribuições do método para o entendimento dos conceitos químicos trabalhados e sua aceitação por parte dos estudantes. Fatareli et al. (2010) finalizam considerando que a aprendizagem cooperativa pode criar condições para um melhor ensino de conteúdos de Química além de contribuir para a formação cidadã consciente e estimular atitudes cooperativas na escola e no ambiente social.

Leite et al. (2013) utilizam o método da Aprendizagem Cooperativa Jigsaw com estudantes do Ensino Médio de uma escola pública do estado de São Paulo e, como resultados, os autores apontam que o ato da argumentação presente em toda a dinâmica promove uma formação mais ampla e enriquecedora, para além dos aspectos conceituais.

O trabalho de Massi, Cerrutti e Queiroz (2013) apresenta como objetivo investigar a aceitação e as contribuições do método Jigsaw para o ensino de Química na graduação. Por meio do desenvolvimento da proposta e da leitura e discussão de artigos, de caráter interdisciplinar, as autoras concluem que a atividade alcançou os objetivos propostos e promoveu uma visão interdisciplinar e mais próxima da realidade em relação à Ciência, além de desenvolver habilidades de escrita. 
No trabalho de Oliveira e Kiouranis (2014) os autores descrevem uma sequência de ensino sobre a aprendizagem cooperativa realizada com estudantes que participam do projeto PIBID do curso de Química de uma universidade pública paranaense, sendo que o objetivo da proposta era compreender melhor essa abordagem e discutir as possibilidades de sua aplicação em sala de aula. Como resultados os autores apontam que os participantes puderam compreender os aspectos práticos e teóricos dos fundamentos dessa abordagem, além de se mostrarem entusiasmados e interessados em utilizá-la nas situações de ensino que desenvolvem.

Winschel et al. (2015) relatam uma experiência com a utilização da aprendizagem cooperativa como abordagem de ensino para facilitar o desenvolvimento de habilidades voltadas para resolver problemas. As atividades foram implementadas em três etapas, com 48 estudantes do segundo semestre de um curso de laboratório de Química Orgânica. Foi utilizado um ambiente online interativo para estruturar as discussões semanais em torno dos problemas. Dentre os resultados, os autores destacam que as discussões e o trabalho em grupo podem ser um recurso útil para a aprendizagem dos conteúdos.

No trabalho de Teodoro, Cabral e Queiroz (2015) os autores descrevem uma atividade didática com o método Jigsaw, desenvolvida em uma disciplina oferecida a graduandos do curso de Química. O objetivo da atividade consistia em investigar a dinâmica das interações estabelecidas entre os estudantes, dentro dos seus respectivos grupos. As transcrições das falas de todos os participantes dos grupos foram classificadas de acordo com as dimensões propostas por Kumpulainen e Mutanen (1999). Os autores destacam que as atividades nos grupos de base proporcionaram aos estudantes um ambiente cooperativo, desenvolvendo suas habilidades acadêmicas, atendendo, portanto, a grande parte das expectativas da aprendizagem cooperativa. A atividade nos grupos de especialistas também proporcionou um ambiente cooperativo, a partir do qual os estudantes tiveram a chance de enfrentar conflitos cognitivos e resolver problemas.

Apresentadas as potencialidades do método jigsaw nos diversos níveis de ensino, quanto às limitações Fatareli et al. (2010) apontam que a aplicação do método em disciplina de química deve ser vista com cautela, uma vez que, devido à natureza do conteúdo a ser tratado, nem sempre é possível adequá-lo a esse método. No entanto, há uma variedade de métodos cooperativos e cabe ao professor optar pelo que melhor se ajusta aos seus objetivos. Outro aspecto a ser considerado é o tempo demandado para a realização da atividade. O professor precisa estar ciente da exigência de tempo mínimo razoável para que a estratégia seja posta em prática de maneira satisfatória. Teodoro, Cabral e Queiroz (2015) também ressaltam que ao optar por estratégias cooperativas em ambientes de ensino, é importante estar consciente que a sua aplicação exige muito esforço, especialmente no que diz respeito à organização e administração das atividades, por parte do docente responsável.

Nesse contexto - de propostas didáticas que fazem uso da abordagem cooperativa -, o objetivo do artigo consiste em apresentar e discutir uma atividade realizada com um grupo de bolsistas PIBID do curso de Química para discutir conceitos de Reações Químicas, utilizando o método Jigsaw. As atividades serviram também para compreensão do método e para que os bolsistas refletissem acerca da implementação desse método nas intervenções realizadas nas escolas participantes do PIBID/Química. 


\section{Desenvolvimento da Atividade}

A atividade relatada nesse artigo foi desenvolvida com bolsistas de um grupo PIBID/Química de uma Universidade Estadual do Paraná. Esse grupo é composto por três supervisores, 16 bolsistas (estudantes do curso de Licenciatura em Química), um coordenador de área e um professor universitário colaborador no projeto. A atividade, gravada em áudio e vídeo, teve duração aproximada de três horas e apresentou a seguinte questão inicial: a massa em uma reação química sempre se conserva? A proposta foi realizada ao longo de uma tarde, durante uma reunião do grupo na qual foram contemplados os seguintes conceitos: conservação de massa; evidências de reações químicas e reações de combustão.

Para uma melhor organização, as professoras responsáveis pela proposta estipularam tempos para a execução das atividades, conforme descrito na Tabela 1.

Tabela 1 - Tempo estimado para cada atividade proposta.

\begin{tabular}{lc} 
Atividades & $\begin{array}{c}\text { Tempo } \\
\text { (minutos) }\end{array}$ \\
\hline 1) Divisão dos bolsistas ${ }^{1}$ nos grupos de \\
base e entrega das funções \\
2) Entrega das hipóteses e elaboração \\
das justificativas \\
3) Formação dos grupos de \\
especialistas \\
4) Entrega e realização das atividades \\
nos grupos de especialistas \\
5) Retorno ao grupo de base e \\
reformulação das hipóteses \\
6) Apresentação oral das conclusões \\
pelos relatores \\
7) Avaliação do método pelos bolsistas \\
8) Discussão final \\
por \\
grupo) \\
10 \\
25
\end{tabular}

Como o grupo em questão é composto por estudantes dos diferentes anos do curso de licenciatura em Química, a formação dos grupos de base, constituídos por quatro integrantes, foi pensada pelas professoras antes do início das atividades. Para garantir a heterogeneidade tomou-se o cuidado de alocar estudantes de diferentes anos em cada um dos grupos. Para cada grupo de base foram entregues quatro cartões enumerados de 1 a 4, correspondentes às funções: (1) Redator cuja função é redigir as respostas do grupo; (2) Mediador - aquele que organiza as discussões no grupo, permitindo que todos possam se expressar, e resolve os conflitos de opinião; (3) Relator - expõe os resultados da discussão; e (4) PortaVoz - tira dúvidas com o professor (Fatareli et al., 2010). Contudo, em um primeiro momento, não foi revelada aos bolsistas a função correspondente a cada número, 
com o intuito de que não a escolhessem de acordo com as suas habilidades. A disposição dos bolsistas nos grupos está representada na Figura 1.

Figura 1 - Diagrama representativo de Aprendizagem Jigsaw.

\begin{tabular}{|c|c|}
\hline $\begin{array}{c}\text { GRUPOS DE BASE: } \\
\text { posicionamento (justificativa) dos } \\
\text { bolsistas com relação às hipóteses }\end{array}$ \\
\hline $\begin{array}{c}\text { GRUPOS DE ESPECIALISTAS: } \\
\text { cada grupo discute de forma mais } \\
\text { aprofundada uma das hipóteses }\end{array}$ \\
\hline $\begin{array}{c}\text { RETORNO AOS GRUPOS DE BASE: } \\
\text { discussão com os membros do } \\
\text { grupo acerca de cada uma das } \\
\text { hipóteses investigadas e } \\
\text { reelaboração das justificativas }\end{array}$ \\
\hline
\end{tabular}

(Fonte: Adaptado de LEITE et al., 2013)

Para os grupos de base, que neste artigo denominamos de GA, GB, GC e GD, foi entregue um quadro (Quadro 1) com quatro hipóteses, em relação as quais os bolsistas deveriam se posicionar a favor ou contra e justificar suas respostas.

Quadro1 - Hipóteses analisadas pelos bolsistas.

\begin{tabular}{|c|l|}
\hline Hipóteses & Descrição \\
\hline Hipótese 1 & $\begin{array}{l}\text { Após a queima de uma folha de papel e de um pedaço de palha de aço a massa, em } \\
\text { cada caso, deverá diminuir, uma vez que se tratam de reações de combustão. }\end{array}$ \\
\hline Hipótese 2 & $\begin{array}{l}\text { Toda reação química pode ser reconhecida por meio de evidências (formação de } \\
\text { gases, mudança de cor, formação de sólido, liberação ou absorção de energia na } \\
\text { forma de calor, liberação de luz, etc.). }\end{array}$ \\
\hline Hipótese 3 & $\begin{array}{l}\text { Reações químicas com liberação de gás realizadas em sistema aberto têm sua massa } \\
\text { diminuída, entretanto, reações químicas com formação de precipitado (corpo de } \\
\text { fundo) em sistema aberto têm sua massa final aumentada, quando comparada a } \\
\text { sua massa inicial. }\end{array}$ \\
\hline Hipótese 4 & $\begin{array}{l}\text { Independentemente de uma reação química acontecer em um sistema aberto ou } \\
\text { fechado a massa deve ser conservada, caso contrário estaria contrariando a Lei de } \\
\text { Lavoisier. }\end{array}$ \\
\hline
\end{tabular}

Após a análise e entrega das justificativas das hipóteses, foram formados os grupos de especialistas, de acordo com o número da função entregue ao grupo de base (Figura 1), com o objetivo de testar as hipóteses.

Cada grupo de especialistas, aqui denominados de G1, G2, G3 e G4, recebeu uma folha contendo uma hipótese, uma atividade experimental e uma complementar (Quadro 2), atividades essas a serem realizadas pelos bolsistas.] 
Quadro 2-Atividades realizadas em cada grupo de especialistas.

\begin{tabular}{|c|c|c|}
\hline Grupos & Atividades & \\
\hline \multirow{3}{*}{1} & Hipótese & $\begin{array}{l}\text { Após a queima de uma folha de papel e de um pedaço de palha de aço } \\
\text { a massa, em cada caso, deverá diminuir, uma vez que se tratam de } \\
\text { reações de combustão. }\end{array}$ \\
\hline & $\begin{array}{c}\text { Atividade } \\
\text { Experimental }\end{array}$ & $\begin{array}{l}\text { 1) Medir a massa de duas folhas de papel antes e após a queima e } \\
\text { anotar. } \\
\text { 2) Medir a massa de um pedaço de palha de aço antes e após a queima } \\
\text { e anotar. }\end{array}$ \\
\hline & $\begin{array}{c}\text { Atividade } \\
\text { Complementar }\end{array}$ & $\begin{array}{l}\text { Leitura do texto: "Stahl ou Lavoisier? A teoria do flogístico" (adaptado } \\
\text { de BELTRAN, 1987). } \\
\text { Após a realização dos experimentos e leitura do texto, descrever as } \\
\text { conclusões do grupo a respeito das reações de combustão realizadas. }\end{array}$ \\
\hline \multirow{3}{*}{2} & Hipótese & $\begin{array}{l}\text { Toda reação química pode ser reconhecida por meio de evidências } \\
\text { (formação de gases, mudança de cor, formação de sólido, liberação ou } \\
\text { absorção de energia na forma de calor, liberação de luz, etc.). }\end{array}$ \\
\hline & $\begin{array}{c}\text { Atividade } \\
\text { Experimental }\end{array}$ & 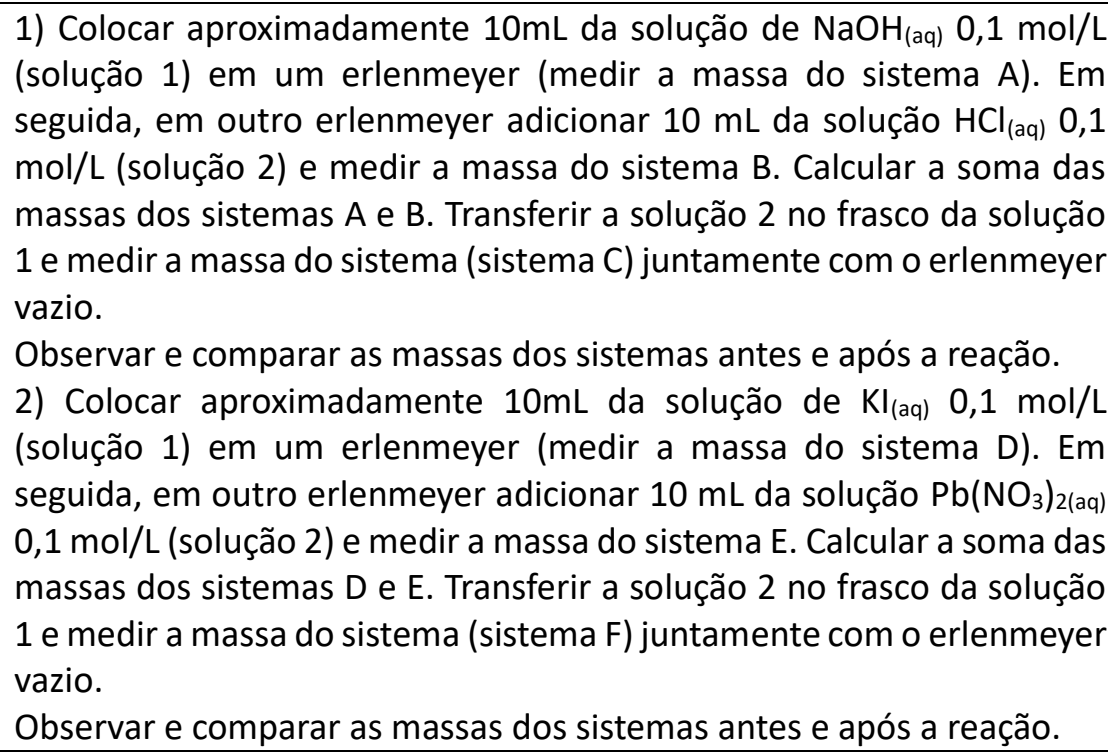 \\
\hline & $\begin{array}{c}\text { Atividade } \\
\text { Complementar }\end{array}$ & $\begin{array}{l}\text { Leitura do texto - "As evidências e o reconhecimento das reações } \\
\text { químicas" (adaptado de MORTIMER e MACHADO, 2012). } \\
\text { Considerando as reações da atividade experimental responda: } \\
\text { a) A existência de uma evidência garante que houve produção de novos } \\
\text { materiais em uma transformação química qualquer? Justifique sua } \\
\text { resposta. } \\
\text { b) Poderiam ocorrer reações sem uma modificação observável no } \\
\text { sistema? Justifique sua resposta. }\end{array}$ \\
\hline \multirow[b]{2}{*}{3} & Hipótese & $\begin{array}{l}\text { Reações químicas com liberação de gás, realizadas em sistema aberto } \\
\text { têm sua massa diminuída; já reações químicas com formação de } \\
\text { precipitado (corpo de fundo) realizadas em sistema aberto têm sua } \\
\text { massa final aumentada, quando comparada a sua massa inicial. }\end{array}$ \\
\hline & $\begin{array}{c}\text { Atividade } \\
\text { Experimental }\end{array}$ & $\begin{array}{l}\text { 1) Medir a massa de dois comprimidos efervescentes. Em um béquer } \\
\text { de } 500 \mathrm{~mL} \text { adicionar } 200 \mathrm{~mL} \text { de água destilada e medir a massa (béquer } \\
\text { + água). Calcular a soma das massas (comprimidos + béquer + água). } \\
\text { Adicionar os comprimidos ao béquer e, após o término da reação, } \\
\text { medir a massa do sistema. } \\
\text { Observar as massas dos sistemas antes e após a reação. }\end{array}$ \\
\hline
\end{tabular}




\begin{tabular}{|c|c|c|}
\hline & & $\begin{array}{l}\text { 2) Colocar aproximadamente } 10 \mathrm{~mL} \text { da solução de } \mathrm{NaOH}_{(\text {aq) }} 0,1 \mathrm{~mol} / \mathrm{L} \\
\text { (solução } 1 \text { ) em um erlenmeyer (medir a massa do sistema } \mathrm{A} \text { ). Em } \\
\text { seguida, em outro erlenmeyer adicionar } 10 \mathrm{~mL} \text { da solução } \mathrm{CuSO} \text { (aq) } 0,1 \\
\text { mol/L (solução } 2 \text { ) e medir a massa do sistema } \mathrm{B} \text {. Calcular a soma das } \\
\text { massas dos sistemas A e B. Transferir a solução } 2 \text { no frasco da solução } \\
1 \text { e medir a massa do sistema C juntamente com o erlenmeyer vazio. } \\
\text { Observar as massas dos sistemas antes e após a reação. }\end{array}$ \\
\hline & $\begin{array}{c}\text { Atividade } \\
\text { Complementar }\end{array}$ & $\begin{array}{l}\text { a) Quais conclusões foram observadas a partir das massas obtidas antes } \\
\text { e após cada reação? } \\
\text { b) Se as reações tivessem se passado em um sistema fechado, por } \\
\text { exemplo, em um tubo de ensaio fechado com uma rolha, os resultados } \\
\text { seriam diferentes? Justifique. }\end{array}$ \\
\hline & Hipótese & $\begin{array}{l}\text { Independentemente de uma reação química acontecer em um sistema } \\
\text { aberto ou fechado a massa deve ser conservada, caso contrário, estaria } \\
\text { contrariando a Lei de Lavoisier. }\end{array}$ \\
\hline 4 & $\begin{array}{c}\text { Atividade } \\
\text { Experimental }\end{array}$ & 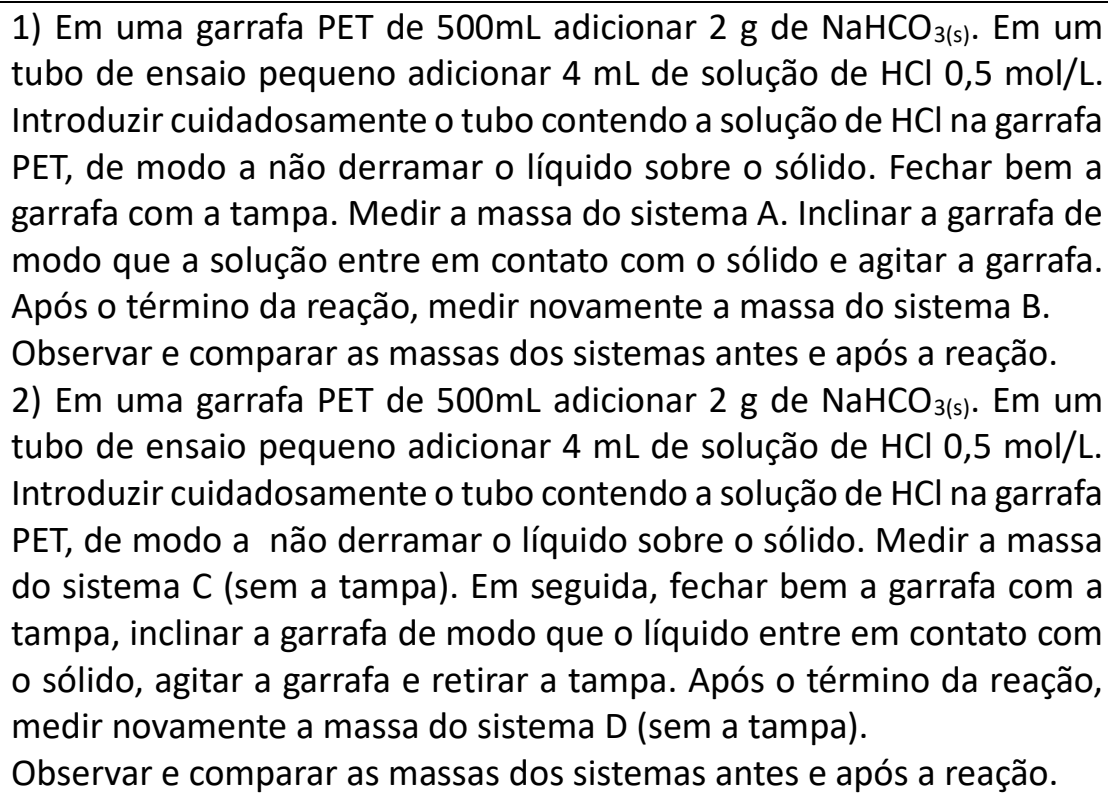 \\
\hline & $\begin{array}{c}\text { Atividade } \\
\text { Complementar }\end{array}$ & $\begin{array}{l}\text { a) Comparando os valores obtidos para as massas do sistema, antes e } \\
\text { depois da reação, nos dois casos (sistema aberto e fechado), o que } \\
\text { vocês podem constatar? } \\
\text { b) A que vocês atribuem a diferença observada? } \\
\text { c) Com os dados obtidos nos experimentos, é possível afirmar que a } \\
\text { massa se conserva em uma reação química? }\end{array}$ \\
\hline
\end{tabular}

Terminadas as atividades, as respostas foram entregues às professoras; os bolsistas retornaram ao grupo de base para apresentarem, aos demais colegas do grupo, suas observações e conclusões sobre os experimentos realizados. Nos grupos de base cada especialista expôs o que realizou e suas conclusões e, na sequência, as hipóteses foram retomadas, (re)considerando as discussões dos especialistas. Os grupos de base analisaram novamente as hipóteses, escrevendo novas justificativas em caso de discordância com o que tinham justificado anteriormente. 
Os relatores apresentaram, ao final, aos demais colegas, as justificativas para as quatro hipóteses. Foi possibilitado que os bolsistas discutissem as justificativas até que chegassem a um consenso para cada hipótese.

Em seguida, para avaliar a estratégia, foi entregue aos bolsistas um questionário constituído de 15 afirmações, baseado no trabalho de Eilks (2005).

Quadro 3 - Afirmações presentes no questionário para avaliar o método Jigsaw.

\begin{tabular}{|c|c|c|c|c|c|}
\hline \multirow{2}{*}{$\begin{array}{l}\text { Afirmações } \\
1 \text { - Eu pude trabalhar com mais independência no formato de aula Jigsaw do } \\
\text { que faço normalmente nas aulas expositivas. }\end{array}$} & CF & C & I & D & DF \\
\hline & & & & & \\
\hline \multicolumn{6}{|l|}{$\begin{array}{l}2 \text { - Eu trabalhei com mais intensidade no formato de aula Jigsaw do que } \\
\text { costumo trabalhar durante as aulas expositivas. }\end{array}$} \\
\hline \multicolumn{6}{|l|}{$\begin{array}{l}3 \text { - Eu prefiro quando o professor discute tópicos com a classe toda (aula } \\
\text { expositiva) do que quando nós temos que trabalhar em pequenos grupos. }\end{array}$} \\
\hline \multicolumn{6}{|l|}{$\begin{array}{l}4 \text { - Eu não gostei de trabalhar no formato de aula Jigsaw, porque meu } \\
\text { trabalho ficou muito dependente do desempenho dos meus colegas. }\end{array}$} \\
\hline \multicolumn{6}{|l|}{5 - Eu acho que o formato de aula Jigsaw é confuso e desestruturado. } \\
\hline \multicolumn{6}{|l|}{$\begin{array}{l}6 \text { - Eu gostei de trabalhar no formato de aula Jigsaw, porque pude trabalhar } \\
\text { junto com outros colegas. }\end{array}$} \\
\hline \multicolumn{6}{|l|}{$\begin{array}{l}7 \text { - O uso de diferentes métodos de ensino (como o formato de aula Jigsaw) } \\
\text { torna nossas aulas mais divertidas e menos cansativas. }\end{array}$} \\
\hline \multicolumn{6}{|l|}{$\begin{array}{l}8 \text { - Acredito que a distribuição de papéis entre os participantes dos grupos de } \\
\text { base (mediador, porta-voz, redator, etc) facilitou a organização do trabalho } \\
\text { em grupo e a realização das atividades. }\end{array}$} \\
\hline \multicolumn{6}{|l|}{$\begin{array}{l}9 \text { - Ter um papel específico no grupo me ajudou a desenvolver novas } \\
\text { habilidades ou aperfeiçoar as que eu já possuía (fala, escrita, organização de } \\
\text { ideias, resolução de conflitos de opinião, etc). }\end{array}$} \\
\hline \multicolumn{6}{|l|}{$\begin{array}{l}10 \text { - Considero que o processamento grupal, realizado no final dos trabalhos } \\
\text { dos grupos de base, é importante para o bom andamento das atividades no } \\
\text { grupo. }\end{array}$} \\
\hline \multicolumn{6}{|l|}{$\begin{array}{l}11 \text { - Eu gostaria de participar novamente de aulas no formato Jigsaw na } \\
\text { disciplina de Química. }\end{array}$} \\
\hline $\begin{array}{l}12 \text { - Eu aprendi mais em meu grupo de especialistas do que com meus colegas } \\
\text { em grupos de base. }\end{array}$ & & & & & \\
\hline
\end{tabular}

Ao final da atividade foi solicitado aos bolsistas que expusessem sua opinião a respeito do método e quanto à possibilidade de utilizá-lo nas escolas em que estavam atuando no PIBID.

\section{Analisando e Discutindo os dados}

Análise das justificativas das hipóteses fornecidas pelos grupos de base 
respostas. Para as hipóteses 1 e 3, que tratavam, respectivamente, da conservação de massa em reações de combustão e de reações com formação de produtos gasosos e sólidos, $50 \%$ dos grupos justificaram corretamente. Com relação à hipótese 2, que investigava evidências de reações químicas, $25 \%$ dos grupos se posicionaram de maneira correta e, com relação à hipótese 4, sobre a conservação de massa em reações com liberação de gás em sistemas aberto e fechado, todos os grupos se posicionaram corretamente. No Quadro 4 apresentamos exemplos das justificativas consideradas incorretas, nessa primeira etapa.

Quadro 4 - Justificativas das hipóteses, da primeira etapa, consideradas incorretas nos grupos de base.

\begin{tabular}{|c|c|c|}
\hline Hipóteses & Exemplos de respostas incorretas & $\begin{array}{l}\% \text { dos } \\
\text { grupos }\end{array}$ \\
\hline Hipótese 1 & $\begin{array}{l}\text { Sim, concordamos, porque em ambos os casos, após a combustão, há perda } \\
\text { de matéria. (GA) } \\
\text { Concordamos, pois, em ambos os casos, ocorre liberação de } \mathrm{CO}_{2} \text { para o } \\
\text { meio. (GC) }\end{array}$ & 50 \\
\hline Hipótese 2 & $\begin{array}{l}\text { Concordamos, pois todas as reações químicas conhecidas por nós podem } \\
\text { ser reconhecidas por evidências. (GB) } \\
\text { Concordamos, pois todas as reações deixam evidências. (GC) } \\
\text { Sim, porém nem sempre podem ser observadas a olho nu. (GD) }\end{array}$ & 75 \\
\hline Hipótese 3 & $\begin{array}{l}\text { [...] reações químicas realizadas em sistema aberto ...nunca terão sua massa } \\
\text { aumentada (GA) } \\
\text { [...] reações químicas com formação de precipitado refletem somente uma } \\
\text { mudança de estado físico }(G C)\end{array}$ & 50 \\
\hline Hipótese 4 & --- & 0 \\
\hline
\end{tabular}

A partir das justificativas apresentadas pelos bolsistas pode-se identificar algumas concepções incorretas acerca das reações químicas, tais como: (GA e GC) em toda reação de combustão há perda de massa no sistema e liberação de gás; (GB e GC) toda reação química é acompanhada de uma evidência; (GD) desconhecimento do significado de evidência química; (GA) reações realizadas em sistema aberto só podem perder massa, ressaltando que o sistema nunca poderá ter sua massa aumentada; (GC) confundem transformação química com transformação física. Concepções similares são também destacadas por Mortimer e Miranda (1995), Rosa e Schnetzler (1998) e Oki, Mendes e Pinheiro (2009). Tais pesquisadores evidenciaram que os alunos, normalmente, prendem-se a aspectos perceptivos das transformações, têm dificuldades em transitar entre os níveis fenomenológico e atômico-molecular e não reconhecem a conservação da massa.

\section{Análise das atividades realizadas nos grupos de especialistas}

$\mathrm{Na}$ segunda etapa, após a entrega das justificativas das hipóteses, foram formados os grupos de especialistas para a realização das atividades experimental e complementar.

O primeiro grupo de especialistas testou a hipótese 1, relacionada à 
papel e a de um pedaço de palha de aço. 0 grupo mediu a massa desses materiais (papel e palha de aço), antes e após a queima, e compararam os resultados, a fim de identificar possíveis mudanças na massa.

Como atividade complementar foi realizada a leitura de um texto e, na sequência, o grupo escreveu as conclusões a respeito das atividades realizadas.

Se fosse possível quantificar a massa de todos os reagentes, inclusive o oxigênio, constataríamos que não haveria perda de massa. Se considerarmos apenas a folha de papel como reagente em sua queima, a massa diminui, pois há perda de produto na forma de gás. Se considerarmos apenas a palha de aço como reagente em sua queima, a massa aumenta, pois o oxigênio é incorporado ao ferro, formando $\mathrm{FeO}(\mathrm{G} 1)$.

Ao final das atividades o grupo pôde concluir que, como as reações (queima do papel e da palha de aço) foram realizadas em sistema aberto, houve perda de massa no primeiro caso, devido à liberação de gás carbônico (CO2) para a vizinhança, e ganho de massa no segundo caso, em virtude da incorporação do gás oxigênio (O2) presente no ar, ao ferro, formando um óxido.

O segundo grupo de especialistas testou a hipótese 2 que abordava algumas evidências de reações químicas. Um dos experimentos realizados consistia em misturar volumes iguais de soluções aquosas de hidróxido de sódio e de ácido clorídrico, ambas de mesma concentração. $O$ outro experimento, semelhante ao primeiro, solicitava que fossem misturadas soluções aquosas de iodeto de potássio e nitrato de chumbo. Para ambos os experimentos os bolsistas mediam a massa dos sistemas antes e após as reações.

Como atividade complementar os bolsistas realizaram a leitura de um texto e responderam a duas questões: a primeira questionava sobre o fato de que a formação de novos materiais em uma transformação química deve sempre ser acompanhada de evidências e, a segunda, acerca da existência de reações químicas sem evidências. Para essas questões, seguem as respostas do grupo:

a) Não, pois determinadas reações não são identificadas visualmente, mas sim necessitam de técnicas mais específicas.

b) Sim. Como ocorreu na parte 1 da prática ao adicionar ácido clorídrico e hidróxido de sódio, sabemos que houve uma reação química, porém essa não pode ser comprovada visualmente (G2).

Ao final das atividades o grupo pôde concluir que há reações químicas que ocorrem sem a presença de evidências, necessitando que sejam realizados testes complementares para comprovar a formação de novas substâncias. Contudo, os bolsistas apresentaram dificuldade em reconhecer o que pode ou não ser considerado uma evidência em uma reação química, ou seja, não apresentaram clareza quanto ao significado da expressão "evidência química".

O terceiro grupo de especialistas investigou a hipótese 3, que abordava a conservação de massa em reações envolvendo liberação de gás e formação de precipitado, ambas em sistema aberto. Um dos experimentos realizados consistia em adicionar comprimidos efervescentes em água. No segundo experimento, deveriam ser misturadas soluções aquosas de hidróxido de sódio e sulfato de cobre (II). Para ambos os experimentos os bolsistas mediam a massa dos sistemas no início e ao término das reações. 
Como atividade complementar os bolsistas responderam a duas questões, uma explicando as conclusões observadas na atividade experimental e outra considerando as mesmas reações, mas em sistema fechado. As respostas do grupo para essas questões estão indicadas a seguir:

a) Na primeira reação houve perda de massa, pela liberação de gás. Na segunda reação houve o aumento de $0,2 \mathrm{~g}$ de massa, no entanto, pode ser considerado como erro de precisão.

b) Se ambas as reações ocorressem em sistema fechado, a primeira teria um resultado diferente e a segunda permaneceria a mesma. Na primeira a massa se conserva (sistema fechado). Na segunda a massa permanece a mesma (sistema fechado ou aberto) (G3).

Finalizadas as atividades, o grupo concluiu que na primeira reação a perda de massa do sistema se deve à liberação de gás carbônico (CO2) e, na segunda, a massa deveria permanecer constante. Este último fato foi justificado pelos bolsistas atribuindo a diferença de massa observada $(0,2 \mathrm{~g})$ a um possível erro experimental. Em relação ao segundo questionamento, acerca de possíveis diferenças nos valores das massas (iniciais e finais) caso as reações ocorressem em sistemas fechados, os bolsistas afirmaram que somente a reação com liberação de gás apresentaria um resultado diferente, uma vez que, nesse tipo de sistema, o gás não seria liberado para o ambiente, apresentando a mesma massa inicial.

O quarto grupo de especialistas investigou a hipótese 4, que tratava da conservação de massa em reações envolvendo liberação de gás, em sistemas aberto e fechado. Ambos os experimentos consistiam em adicionar bicarbonato de sódio em uma garrafa com ácido clorídrico. No entanto, no primeiro, a reação ocorria em sistema aberto (garrafa sem tampa) e, no segundo, em sistema fechado (garrafa com tampa). Para ambos os experimentos os bolsistas mediam a massa dos sistemas antes e após as reações.

Como atividade complementar os bolsistas responderam a três questões: i) a primeira sobre as conclusões observadas nos dois casos (sistemas aberto e fechado); ii) na segunda, eles tinham que dar uma justificativa das diferenças observadas; iii) na terceira, tinham que expor a constatação a respeito da conservação de massa nas reações químicas. Para essas questões, seguem as respostas do grupo:

a) No sistema fechado as massas permaneceram iguais e no sistema aberto a massa final diminuiu.

b) Como a reação forma gás, evidenciado pela efervescência, consideramos que a diferença de massa se deve a massa do gás liberado.

c) Não se conserva. Isso foi observado no sistema aberto, onde houve a liberação de gás para o ambiente e, consequentemente houve uma redução da massa do sistema (G4).

Ao final das atividades o grupo concluiu que reações com formação de produtos gasosos em sistema aberto têm sua massa final diminuída, quando comparada à inicial, uma vez que o gás é liberado para o ambiente. Entretanto, o grupo apresentou dificuldades em entender que a massa de uma reação química sempre se conserva, independentemente do tipo de sistema (aberto ou fechado). A perda de massa observada na balança é justificada por produtos gasosos 
liberados para o ambiente, o que não compromete a conservação de massa da reação.

\section{Análise das reformulações das hipóteses realizadas pelos grupos de base}

Após a realização e entrega das atividades pelos grupos de especialistas, os bolsistas retornaram ao grupo de base. Cada bolsista apresentou aos demais as conclusões das tarefas realizadas no grupo de especialistas que participou. Dessa forma, todas as atividades investigadas pelos grupos de especialistas foram compartilhadas no grupo de base. Em seguida, cada grupo de base analisou as hipóteses novamente, reformulando-as quando julgavam necessário.

Ao analisarmos as justificativas finais apresentadas pelos grupos de base, observamos que, para a primeira hipótese, os grupos compreenderam, de uma forma geral, que reações de combustão podem ter sua massa aumentada (queima de um pedaço de palha de aço) ou diminuída (queima de uma folha de papel), justificadas pela incorporação da massa do oxigênio que não foi medido antes (GD) e pela liberação de $\mathrm{CO} 2$ e vapor de água (GB), respectivamente. Contudo, alguns erros ainda foram detectados nas justificativas de alguns grupos. Com relação à queima do papel, um grupo menciona que há uma diferença no peso inicial e final devido à perda do oxigênio para o meio, já que está em estado gasoso (GA). Para a queima da palha de aço foi justificado que o aumento da massa final se deve à formação de $\mathrm{FeO}$ que ficou retido na palhinha (GA) e que a massa de oxigênio deveria ser pesada para fazer valer a lei da conservação de massas (GC).

O erro mencionado por GA na queima do papel está em justificar a perda de massa do sistema final à liberação de gás oxigênio e não de dióxido de carbono, produto de reações de combustão de hidrocarbonetos, além de utilizar o conceito de peso como sinônimo de massa. Para o segundo experimento, GA afirma que o FeO (óxido de Ferro II) fica incorporado à palha de aço e não que a palha de aço, após ser queimada, se transforma em FeO. Para GC, o equívoco está em mencionar que só é possível haver a conservação de massa dos sistemas (inicial e final) se os reagentes gasosos forem contabilizados no sistema inicial, independentemente de o sistema ser aberto ou fechado. Essas respostas equivocadas podem ser fruto do não entendimento do especialista que, ao discutir no grupo de base, repassa suas dúvidas e concepções.

No que se refere à segunda hipótese, as justificativas também foram satisfatórias, para três grupos que mostraram entender que nem toda reação química possui evidências, pois na realização do experimento $1(\mathrm{HCl}+\mathrm{NaOH})$ ocorre uma reação de neutralização (formação de novos produtos), mas não há evidências (GC), e algumas (reações) necessitam de técnicas mais precisas para a verificação da ocorrência da reação (GB).

O único grupo que justifica incorretamente menciona que em todas as reações químicas acontece algum tipo de transformação evidente, mas ela não necessariamente é visível a olho nu (GD).

Os bolsistas desse grupo destacam não entender que evidências são sinais observáveis, indicativos de interações, e que há interações que, apesar de não serem acompanhadas de evidências, provocam transformações químicas (GEPEQ, 1999, 2008). 
Para a terceira hipótese, todos os grupos de base entenderam que reações químicas com liberação de gás realizadas em sistema aberto têm sua diminuição de massa justificada pela liberação de gás para o ambiente. Contudo, ao analisarem reações químicas com formação de precipitado (corpo de fundo) em sistema aberto, dois grupos mencionaram que a formação de precipitado se deve apenas a uma mudança de estado físico (GC e GD). Esses bolsistas justificaram que a formação de precipitado se deve a uma mudança de estado físico dos reagentes presentes no sistema e não à formação de outras substâncias que são insolúveis no solvente em questão.

Para a quarta hipótese, todos os grupos de base justificaram corretamente, explicando que a diferença de massa observada na balança é devido ao gás liberado, mas que esse fato não contraria a Lei de Lavoisier, a qual diz que a massa, em uma reação, se conserva.

Finalizada a reformulação das justificativas das hipóteses, os redatores entregaram-nas às professoras. Em seguida, o relator de cada grupo de base expôs os resultados da discussão de cada uma das hipóteses para os demais bolsistas, sendo realizada uma discussão geral acerca das atividades e dos conceitos químicos envolvidos. Portanto, os erros registrados nas justificativas reformuladas foram (re)discutidos no grande grupo.

\section{Avaliação do método de Jigsaw pelos estudantes participantes da pesquisa}

Para avaliar o método de aprendizagem cooperativa, os bolsistas responderam individualmente ao questionário (Quadro 3) e foi realizada uma discussão geral acerca do método com o objetivo de que todos expressassem suas opiniões a seu respeito.

Apresentamos, na Figura 2, as respostas fornecidas para as afirmações relacionadas à opinião dos bolsistas com relação ao método Jigsaw. Para uma melhor discussão, agrupamos as respostas em três categorias: respostas em que os bolsistas concordam ou concordam fortemente; respostam em que eles se posicionam de forma indecisa e respostas em que discordam ou discordam fortemente. Realizamos esse agrupamento a fim de apontar aspectos positivos e negativos do método. 
Figura 2 - Respostas fornecidas pelos bolsistas ao questionário de avaliação do método Jigsaw.

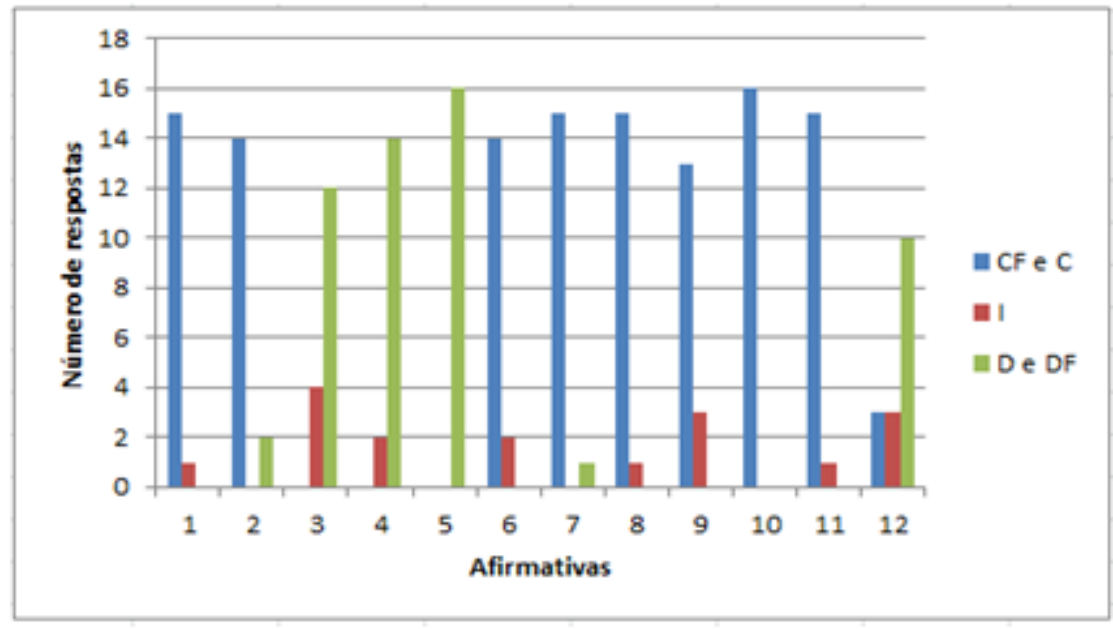

Quanto às afirmações 1, 2 e 6, referentes à conduta dos bolsistas no processo de aprendizagem pelo método Jigsaw, 15 bolsistas (94\%) afirmaram aprender com mais independência quando comparado às aulas expositivas; 14 bolsistas (88\%) mencionaram tanto trabalhar com mais intensidade nesse formato de aula quanto apreciar o trabalho em grupos.

Quanto às afirmações 8, 9 e 10, relacionadas à distribuição dos papéis entre os participantes, 15 bolsistas (94\%) destacaram que a distribuição de funções entre os participantes do grupo facilitou a organização do trabalho e a realização das atividades; 13 bolsistas (81\%) alegaram que ter um papel específico no grupo ajudou a desenvolver novas habilidades ou aperfeiçoar as que já possuíam; e 16 bolsistas (100\%) relataram que o processamento grupal, realizado no final dos trabalhos dos grupos de base, é importante para o bom andamento das atividades no grupo.

Para as afirmações 3, 4, 5 e 7, que comparam o método Jigsaw à aula expositiva, 12 bolsistas (75\%) mencionaram que preferem trabalhos em grupos a aulas em que o professor discute tópicos com os estudantes; 14 bolsistas (88\%) indicaram que a dependência entre o desempenho dos colegas no formato de aula Jigsaw não compromete a estratégia; 16 bolsistas (100\%) afirmaram que o formato de aula Jigsaw é claro e bem estruturado; e 13 bolsistas (82\%) alegaram que o uso de diferentes métodos de ensino, como o formato de aula Jigsaw, torna as aulas mais interessantes e compreensíveis.

Por fim, 10 bolsistas (63\%) expuseram ter aprendido mais com os colegas no grupo de base do que no grupo de especialistas e 15 bolsistas (94\%) relataram que gostariam de participar novamente de aulas no formato Jigsaw no curso de Química.

A seguir, apresentamos algumas falas dos bolsistas coletadas durante a discussão realizada após responderem ao questionário final (Quadro 3).

Baseando-se nas falas de B1, B10 e B11, nota-se que esses destacam a relevância da organização da proposta para o bom desenvolvimento do método. 
- Uma coisa muito legal foi o tipo de trabalho em grupo porque normalmente em um trabalho em grupo um faz e os demais não, e, nesse, todo mundo acaba participando, pois tem que entender para voltar no grupo e explicar, relatar o que fez. (B10)

- Realmente o trabalho que dá é na escolha das atividades.

- No grupo de especialistas o experimento e o texto de apoio ajudam muito. (B11)

Alguns bolsistas (B4, B8 e B15) relataram o papel do professor nesse tipo de proposta, bem como a possibilidade de (re)significação dos conceitos no decorrer das atividades nos diferentes grupos (base e especialistas).

- Esse tipo de atividade desfaz a ideia simplista de que em toda queima há diminuição de massa. (B4)

- O professor tem que estar atento às discussões, porque um erro conceitual do especialista compromete a aprendizagem dos demais. (B8)

- Usar os erros experimentais para ampliar as discussões sobre os conceitos. (B8)

- Obriga a gente a entender, pois tem que explicar para os outros depois. (B15)

Para B15 o método contribui para o desenvolvimento de outras habilidades.

- Ficou tudo certinho, porque teve que falar quem não gosta de falar, teve que escrever quem não gosta de escrever. (B15)

Por sua vez, B11 evidencia seu interesse pelo método Jigsaw, ressaltando que diferentes métodos de ensino tornam as aulas prazerosas e mais compreensíveis. B11 também destaca a importância da articulação teoria-prática, uma vez que o grupo já havia lido e discutido artigos que referenciavam o método.

- Eu gostei... foi a melhor reunião do PIBID... foi muito divertido. Quando você lê sobre a metodologia é uma coisa, mas quando você a desenvolve em grupo dá outra visão. (B11)

De forma geral, os bolsistas apreciaram e compreenderam o método, identificaram a importância do papel do professor na elaboração, organização e desenvolvimento de uma proposta envolvendo o método Jigsaw e manifestaram interesse em implementar o método nas escolas em que participavam.

\section{Considerações Finais}

O artigo em questão tinha como objetivo apresentar e discutir uma atividade empregando o método Jigsaw, abordando conceitos de reações químicas, além de contribuir para a compreensão do método e refletir acerca da sua implementação nas intervenções realizadas pelo PIBID/Química nas escolas participantes. 
Por meio da análise da atividade, observamos que o método Jigsaw pode propiciar uma forma mais organizada de trabalho em grupos cooperativos, uma vez que os integrantes atuam com funções específicas. As diferentes funções exercidas pelos participantes dos grupos possibilitam o desenvolvimento ou aperfeiçoamento de habilidades, tais como: fala, escrita, organização de ideias, resolução de conflitos de opinião; habilidades importantes à formação qualquer cidadão.

Além disso, o método contribui para a atuação ativa dos estudantes no processo de aprendizagem e estimula a função de mediador do professor ao elaborar, organizar e desenvolver as atividades.

As discussões realizadas nos grupos de base e de especialistas possibilitaram condições de (re)significação conceitual, além de propiciarem a discussão de conceitos com os colegas, o que favorece a apropriação e reorganização do aprendido de forma mais significativa.

A avaliação do método realizada pelos bolsistas mostrou que ele contribuiu para melhorar a compreensão dos conceitos abordados, além de tornar as aulas mais interessantes e compreensíveis. Os bolsistas envolvidos na atividade demonstraram compreender tanto os aspectos teóricos quantos os práticos da proposta.

Nesse sentido, ressaltamos que o método Jigsaw pode ser implementado nas escolas para abordar múltiplos conceitos científicos, no entanto, algumas questões devem ser consideradas, como o tempo necessário para a realização das atividades, o empenho e a disposição do professor para elaborar, organizar e coordenar uma atividade dessa natureza.

Nessa acepção, acreditamos que o método apresenta diversos aspectos positivos que podem ser potencializado, uma vez que estimula atitudes de estudantes e professores para a promoção do aprendizado de química, tanto na Educação Básica quanto no Ensino Superior. 


\title{
Exploring concepts of chemical reactions through of the Jigsaw Method of Cooperative Learning
}

\begin{abstract}
This article describes a proposal of activity based on cooperative learning using the Jigsaw method. Such activity, developed with students of the PIBID/Chemistry undergraduate program of a public university of Paraná state, addressed concepts of Chemical Reactions and discussed the possibilities of implementation of this method in high school classes. The results, obtained by means of a questionnaire and discussions, suggest that the Jigsaw can: propitiate a more organized way to work in cooperative groups, since members work with specific functions which are essential to the group; create opportunities for development and improvement of skills such as speaking, writing, organization of ideas, and resolution of conflicts of opinion; enable conditions of conceptual (re)signification through the discussions in the different groups (basic and expert); contribute so that students have a more active role in the learning process; and stimulate the teacher's role of mediator to prepare, organize and develop the proposal involving the method.
\end{abstract}

KEYWORDS: Jigsaw. PIBID. Chemistry reactions. Cooperative learning. 


\section{NOTAS}

1 Neste artigo denominamos como bolsistas tanto os alunos da graduação quanto os supervisores das escolas participantes do projeto PIBID/Química.

\section{REFERÊNCIAS}

ANDRADE, C. N. R. Aprendizagem Cooperativa: Estudo com alunos do 3.드B. 2011. 239f. Dissertação. (Mestrado em Ensino das Ciências) - Escola Superior de Educação de Bragança.. Instituto Politécnico de Bragança. Escola Superior de Educação. Bragança - Portugal. 2011

ARONSON, E.; BLANEY, N.; STEPHINS, C.; SIKES, J.; SNAPP, M. The jigsaw classroom. Beverly Hills: Sage, 1978.

BARBOSA, R. M. N.; JÓFILI, Z. M. S. Aprendizagem cooperativa e ensino de química: Parceria que dá certo. Ciência \& Educação, v. 10, n. 1, p. 55-61, 2004.

BELTRAN, N. O. Combustão: duas interpretações diferentes. Revista de Ensino de Ciências. v. 19, p. 47-49, out, 1987.

BESSA, N.; FONTAINE, A. Cooperar para aprender: Uma introdução à aprendizagem cooperativa. Porto: Edições ASA, 2002.

COCHITO, M. I. G. S. Cooperação e aprendizagem: educação intercultural. Lisboa: ACIME, 2004. 198p. Disponível em: < https://infoeuropa.eurocid.pt/files/database/000040001000041000/000040616.pdf>. Acesso em 26 abr. 2016.

DÍAZ-AGUADO, M. J. A Educação intercultural e aprendizagem cooperativa. Porto: Porto Editora, 2000.

EILKS, I. Experiences and reflections about teaching atomic structure in a jigsaw classroom in lower secondary school chemical lessons. Journal of Chemical Education, v. 82, n. 2, p. 313-319, 2005.

FATARELI, E. F.; FERREIRA, L. N. A.; FERREIRA, J. Q.; QUEIROZ, S. L. Método Cooperativo de Aprendizagem Jigsaw no Ensino de Cinética Química. Química Nova na Escola, v. 32, n. 3, p. 161-168, 2010. 2003. 
GEPEQ. Interações e Transformações I: elaborando conceitos sobre transformações químicas - Guia do professor/GEPEQ/IQ - USP. 5 ed. São Paulo: Editora da Universidade de São Paulo, 2008.

GEPEQ. Interações e Transformações: Química - Ensino Médio: Livro do Aluno: Guia do Professor/GEPEQ. 5 ed. São Paulo: Editora da Universidade de São Paulo, 1999.

JOHNSON, D.W. e JOHNSON, R.T. Instructional goal structure: cooperative, competitive or individualistic. Review of Educational Research, v. 44, p. 213-240, 1974

JOHNSON, D.W.; JOHNSON, R.T. e HOLUBEC, E.J. Los nuevos círculos del aprendizaje: la cooperación en el aula y la escuela. Virginia: Aique, 1999.

KUMPULAINEN, K.; MUTANEN, M. The situated dynamics of peer group interaction: an introduction to an analytic framework. Learning and Instruction, v. 9, p. 449-473, 1999.

LEITE, I. S.; LOURENÇO, A. B.; LICIO, J. G.; HERNANDES, A. C. Uso do método cooperativo de aprendizagem Jigsaw adaptado ao ensino de nanociência e nanotecnologia. Revista Brasileira de Ensino de Física, v. 35, n. 4, 4504, 2013.

MASET, P. P. La escuela inclusiva y el aprendizaje cooperativo. 2003. Disponível em: <http://www.deciencias.net/convivir/1.documentacion/D.cooperativo/ Escuelainclusiva_ACooperativo_Pujolas_17p.pdf>. Acesso em: 14 dez. 2015.

MASSI, L.; CERRUTTI, B. M.; QUEIROZ, S. L. Metodologia de Ensino Jigsaw em disciplina de Química Medicinal. Química Nova, v. 36, n. 6, p. 897-904, 2013.

MORTIMER, E. F.; MACHADO, A. H. Química. v. 1. São Paulo: Scipione, 2012, p. 211-212.

MORTIMER, E. F.; MIRANDA, L. C. Transformações: concepções de estudantes sobre reações químicas. Química Nova na Escola, n.2, p. 23-26, nov, 1995.

OKI, M. C. M.; MENDES, M. P. L.; PINHEIRO, B. C. S. Transformações química: concepções e ensino. In: 7ํ Simpósio Brasileiro de Educação Química. Salvador/Bahia. 2009. 
Simpósio Nacional de Ensino de Ciência e Tecnologia, 2014, Ponta Grossa. Disponível em: <www.sinect.com.br/2014/down.php?id=3198\&q=1>. Acesso em 26 abr. 2016.

ROSA, M. I. F. P. S.; SCHNETZLER, R. P. Sobre a importância do conceito transformação química no processo de aquisição do conhecimento químico. Química Nova na Escola, n. 8, nov. 1998.

SÁ, D. M. B. Aprendizagem Cooperativa - Aplicação dos métodos Jigsaw e Graffiti Cooperativo com alunos do 50 ano de escolaridade. 2015. 141f. Dissertação (Mestrado em Ensino das Ciências). Instituto Politécnico de Bragança - Escola Superior de Educação. Bragança. Fevereiro de 2015.

TEODORO, D. L.; CABRAL, P. F. O.; QUEIROZ, S. L. Atividade Cooperativa no Formato Jigsaw: um estudo no Ensino Superior de Química. ALEXANDRIA Revista de Educação em Ciência e Tecnologia, v. 8, n. 1, p. 21-51, maio, 2015.

VALADARES, J. A.; MOREIRA, M. A. A teoria da aprendizagem significativa: Sua fundamentação e implementação. Coimbra: Edições Almedina. 2009.

WINSCHEL, G. A.; EVERETT, R. K.; COPPOLA, B. P.; SHULTZ, G. V.; LONN, S. Using Jigsaw-Style Spectroscopy Problem-Solving To Elucidate Molecular Structure through Online Cooperative Learning. J. Chem. Educ., v. 92, n. 7, p. 1188-1193, 2015.

Recebido: 21 jun. 2016.

Aprovado: 15 dez. 2016.

DOI: $10.3895 /$ rbect.v9n1.4073

Como citar: BROIETTI, F. C. D.; SOUZA, M. C. C. Explorando conceitos de Reações Químicas por meio do

Método Jigsaw de Aprendizagem Cooperativa. Revista Brasileira de Ensino de Ciência e Tecnologia, v. 9

n. 3, 2016. Disponível em: <https://periodicos.utfpr.edu.br/rbect/article/view/4073>. Acesso em: xxx.

Correspondência:

Direito autoral: Este artigo está licenciado sob os termos da Licença Creative Commons-Atribuição 4.0

Internacional. 